Tropical Journal of Pharmaceutical Research September 2020; 19 (9): 1871-1877

ISSN: $1596-5996$ (print); 1596-9827 (electronic)

(C) Pharmacotherapy Group, Faculty of Pharmacy, University of Benin, Benin City, 300001 Nigeria.

Original Research Article

http://dx.doi.org/10.4314/tjpr.v19i9.11

\title{
LncRNA MALAT1: A potential therapeutic target in DSS- induced ulcerative colitis progression in vitro
}

\author{
Baoqin Zhang, Tiantian Li, Chao Wang, Jing Han, Baiqing Wang, Guangbin \\ Sun* \\ Department of Gastroenterology, Tianjin Fifth Central Hospital, Tianjin 300450, China
}

*For correspondence: Email: cvb7853@126.com; Tel: +86-18273509271

Sent for review: 3 March 2020

Revised accepted: 26 March 2020

\begin{abstract}
Purpose: Ulcerative colitis is a severe disease affecting human health worldwide. Studies have shown that IncRNA MALAT1 has a significant correlation with breast, pancreatic, colon and liver cancers, but its effects on colitis is yet to be discovered. In this study, the potential role of IncRNA MALAT1 and the underlying molecular mechanism in DSS-induced colitis were investigated in vitro.

Methods: Colorectal mucosal cell line FHC was induced with dextran sulphate sodium (DSS) to form an in vitro colitis model. Transfection procedure was employed to up-or down-regulate the expressions of IncRNA MALAT1 or miR-30c-5p in FHC cells. Cell viabilities were detected by CCK-8 assay. RT-qPCR was applied for evaluating gene expressions in normal FHC and DSS-induced FHC cell lines, while protein expression levels of target genes were examined by Western blot analysis. Starbase was used to predict the molecular interaction between MALAT1 and miR-30c-5p, while luciferase reporter assay was utilized to verify the binding sites between the two genes.

Results: Expression of MALAT1 in the DSS-induced FHC cells was high with low cell viabilities, compared to the normal FHC cells. In the DSS-induced colitis-like FHC cells, overexpression of MALAT1 inhibited cell viabilities, while its downregulation promoted it. MiR-30c-5p directly targets MALAT1 and inhibited its expression in DSS-treated FHC cells. Upregulation of miR-30c-5p increased cell viabilities. Bcl-xL expression was inhibited by the up-regulation of MALAT1, while that of Bax was enhanced and the mimics of miR-30c-5p reversed these observations, suggesting that the enhancement of apoptosis promoted by oe-MALAT1 could be inhibited by miR-30c-5p. The interaction between MALAT1 and miR-30c-5p regulated NF-KB/TGF- $\beta /$ Wnt- $\beta$-catenin signaling pathway.

Conclusion: Overexpression of MALAT1 led to inhibition of cell viability, while apoptosis and inflammation were promoted by targeting miR-30c-5p via NF-KB/TGF- $\beta /$ Wnt- $\beta$-catenin signaling pathway. These findings suggest MALAT1 as a therapeutic target for treating colitis.
\end{abstract}

Keywords: Colitis, MALAT1, miR-30c-5p, NF-kB/TGF- $\beta /$ Wnt- $\beta$-catenin

This is an Open Access article that uses a fund-ing model which does not charge readers or their institutions for access and distributed under the terms of the Creative Commons Attribution License (http://creativecommons.org/licenses/by/4.0) and the Budapest Open Access Initiative (http://www.budapestopenaccessinitiative.org/read), which permit unrestricted use, distribution, and reproduction in any medium, provided the original work is properly credited.

Tropical Journal of Pharmaceutical Research is indexed by Science Citation Index (SciSearch), Scopus, International Pharmaceutical Abstract, Chemical Abstracts, Embase, Index Copernicus, EBSCO, African Index Medicus, JournalSeek, Journal Citation Reports/Science Edition, Directory of Open Access Journals (DOAJ), African Journal Online, Bioline International, Open-J-Gate and Pharmacy Abstracts

\section{INTRODUCTION}

Ulcerative colitis (UC) and Crohn's disease are the two kinds of ailments in inflammatory bowel diseases in human bodies. UC is a spontaneous chronic inflammatory lesion with invading mucosa and submucosa in rectums and colons [1]. The clinical symptoms are diarrhea, mucopurulent bloody stool and abdominal pain [2]. However, the mechanisms of UC are still 
unclear, but it might have connections with the environment, microorganisms, races, genetic susceptibility and immunological factors $[3,4]$. UC is commonly divided into three types by Montreal Degree Classification of Diseases; ulcerative proctitis, left side UC and extensive UC [5]. As a chronic disease, UC not only increases medical costs, but also affects qualities of life. Therefore, it is important to build models of UC for unveiling the etiologies and mechanisms. Colitis models induced by dextran sulphate sodium (DSS) is the most widely used agent due to the convenience, cheap price and high success rates $[6,7]$. Besides that, clinical manifestations, positions of disease and pathological characteristics of models are similar to UC in human bodies [8].

Long non-coding RNA is a kind of RNA with full length over 200 nucleotides and has no coding abilities of proteins [9]. Metastasis-associated lung adenocarcinoma transcript 1 (MALAT1) which was first discovered in non-small cell lung cancer is commonly expressed in cells and tissues in humans and mice, especially neural system [10,11]. MALAT1 had significant correlation with breast, pancreatic, colon and liver cancers and so on [12,13]. MALAT1 was recently discovered to be co-expressed with IncRNA ANRIL in ulcerative colitis and was disclosed to be upregulated in colitis tissues from patients, compared to the normal ones and might contribute to colitis progression [14]. The present study was aimed at exploring the potential roles of MALAT1 in UC and also investigating the underlying molecular mechanism using a DSSinduced colitis model.

\section{EXPERIMENTAL}

\section{Cell culture}

Human normal colorectal mucosal cell line FHC was purchased from ATCC (USA). Cells were cultured in RPMI-1640 medium with $10 \%$ fetal bovine serum (FBS) (Thermo Fisher, USA) in incubator at $37{ }^{\circ} \mathrm{C}, 5 \% \mathrm{CO}_{2}$. Then, cells were collected and rinsed with PBS twice. Afterwards, the cells were seeded into 12-well plate with $5 \times 10^{5}$ cells per well and cultured with serum-free medium for $10 \mathrm{~h}$. An aliquot of $50 \mu \mathrm{g} / \mathrm{ml}$ DSS was added into plate for treating cells for $12 \mathrm{~h}$ to form colitis-like DSS-FHC cells. Finally, cells were rinsed by PBS twice and collected for subsequent experiments.

\section{Cell transfection}

DSS-induced FHC cells were used for transfection, which were achieved by employing Lipofectamine $^{\mathrm{TM}} 3000$ Transfection Reagent
(Invitrogen, CA, USA). Negative controls or SiRNAs of MALAT1, pcDNA3.1-MALAT1 and pcDNA3.1 negative control were synthesized by FitGene Co. (Shanghai, China) and $20 \mathrm{nM}$ of each was used with $1.5 \mu \mathrm{L}$ Lipofectamine ${ }^{\mathrm{TM}} 3000$ in each plate. The media were replaced with 10 $\%$ FBS RPMI-1640 medium, 6 h after transfection. Plasmids of miR-30c-5p mimics, miR-30c-5p inhibitor, inhibitor NC and mimics NC were provided by FitGene Co. (Shanghai, China) and were transfected into the DSS-induced FHC cells using Lipofectamine ${ }^{\mathrm{TM}} 3000$ Transfection Reagent.

\section{RT-qPCR}

Cells in log phase were selected. An aliquot of 1 $\mathrm{ml}$ Beyozol (Beyotime, Shanghai, China) and 0.2 $\mathrm{ml}$ chloroform were added one after the other and the top water phase was gathered to quantify the extracted RNAs. Then, $4 \mu \mathrm{g}$ of total RNAs were reverse transcribed into cDNAs through BeyoRT ${ }^{\mathrm{TM}}$ II First Strand cDNA Synthesis Kit (Beyotime, Shanghai, China). Nucleotide sequences of primers used for quantitative polymerase chain reaction were presented in Table 1. GAPDH. a housekeeping gene was used for normalization. Conditions of RT-qPCR were: pre-denaturation at $95{ }^{\circ} \mathrm{C}$ for 10 min, followed by 40 cycles of denaturation at 95 ${ }^{\circ} \mathrm{C}$ for $15 \mathrm{~s}$, annealing at $60{ }^{\circ} \mathrm{C}$ for $1 \mathrm{~min}$. The relative expressions of genes were determined through $2^{-\triangle \triangle \mathrm{Ct}}$ methods.

\section{CCK-8 assay}

After transfection, the cells were collected and planted into 96-well, plated with $1 \times 10^{5}$ cells per well. Then, the cells were cultured for $24 \mathrm{~h}$ at 27 ${ }^{\circ} \mathrm{C}, 5 \% \mathrm{CO}_{2}$. Thereafter, $10 \mu \mathrm{l} \mathrm{CCK}-8$ reagent (Thermo Fisher, USA) was added into the plate and cultured for $3 \mathrm{~h}$. Microplate reader (Thermo Fisher, USA) was applied to detect optical density (OD) values at $490 \mathrm{~nm}$ wavelength.

\section{Luciferase report assay}

Starbase V2.0 (http://starbase.sysu.edu.cn/star base2/index.php) was used to predict the potential binding between IncRNA MALAT1 and miR-30c-5p. The DSS-induced FHC cells were collected and cell number was adjusted to $5 \times 10^{5}$ cells per well, which were seeded into 24-well plate with serum free medium. Afterwards, the DSS-induced FHC cells were co-transfected with miR-30c-5p mimics or mimics NC and MALAT1wt or MALAT1-mut using Lipofectamine ${ }^{\mathrm{TM}} 3000$. Luciferase activities were detected by Dual Luciferase Reporter Assay System (Progema, USA).

Trop J Pharm Res, September 2020; 19(9): 1872 
Table 1: Real time-qPCR primer sequences

\begin{tabular}{|c|c|c|}
\hline $\begin{array}{l}\text { Target } \\
\text { gene }\end{array}$ & Direction & Nucleotide sequences \\
\hline \multirow[t]{2}{*}{$\begin{array}{l}\text { MALAT } \\
1\end{array}$} & Forward & $\begin{array}{l}\text { 5'- } \\
\text { TGCGAGTTGTTCTCCGTCT } \\
\text { A-3' }\end{array}$ \\
\hline & Reverse & $\begin{array}{l}5 \text { '- } \\
\text { TATCTGCGGTTTCCTCAAG } \\
\text { C -3' }\end{array}$ \\
\hline \multirow[t]{2}{*}{$\begin{array}{l}\text { miR- } \\
30 c-5 p\end{array}$} & Forward & $\begin{array}{l}\text { 5'- } \\
\text { ACACTCCAGCTGGGTGTAA } \\
\text { ACATCCTACACTC-3' }\end{array}$ \\
\hline & Reverse & $\begin{array}{l}\text { 5- } \\
\text { CTCAACTGGTGTCGTGGAG } \\
\text { TCGGCAATTCAGTT } \\
\text { GAGGCTCAGAG-3' }\end{array}$ \\
\hline \multirow[t]{2}{*}{ U6 } & Forward & $\begin{array}{l}\text { 5'- } \\
\text { GCTTCGGCAGCACATCTCA } \\
\text { TAAAAT-3' }\end{array}$ \\
\hline & Reverse & $\begin{array}{l}\text { 5'- } \\
\text { CGCTTCACGATTTGCGTGT } \\
\text { CAT-3' }\end{array}$ \\
\hline \multirow[t]{2}{*}{ Bcl-xL } & Forward & $\begin{array}{l}\text { 5'- } \\
\text { CCCCAGAAGAAACTGAACC } \\
\text { A-3' }\end{array}$ \\
\hline & Reverse & $\begin{array}{l}\text { 5'- } \\
\text { AGTTTACCCCATCCCGAAA } \\
\text { G-3' }\end{array}$ \\
\hline \multirow[t]{2}{*}{ Bax } & Forward & $\begin{array}{l}\text { 5'- } \\
\text { GGAGGAAGTCCAGTGTCC } \\
\text { AG-3' }\end{array}$ \\
\hline & Reverse & $\begin{array}{l}\text { 5'- } \\
\text { TGCAGAGGATGATTGCTGA } \\
\text { C-3' }\end{array}$ \\
\hline \multirow[t]{2}{*}{$\begin{array}{l}\text { GAPD } \\
\mathrm{H}\end{array}$} & Forward & $\begin{array}{l}\text { 5'- } \\
\text { ACCCAGAAGACTGTGGATG } \\
\text { G-3' }\end{array}$ \\
\hline & Reverse & $\begin{array}{l}\text { 5'- } \\
\text { TCAGCTCAGGGATGACCTT } \\
\text { G-3' }\end{array}$ \\
\hline
\end{tabular}

\section{Western blot}

Cells after transfection were lysed by RIPA Lysis Buffer (Beyotime, Shanghai, China) for $30 \mathrm{~min}$ on ice. After centrifugation, supernatant was collected, which were the proteins in the cells. An aliquot of $5 \mu \mathrm{g}$ total proteins were separated by 5 $\%$ SDS-PAGE and transferred into PVDF membranes (Thermo Fisher, USA). Then, the membranes were blocked by skimmed milk powder for $1 \mathrm{~h}$ and incubated with primary antibodies overnight at $4^{\circ} \mathrm{C}$. Primary antibodies were shown as follow: anti-Wnt1 (1:1500; ab15251), anti-NF-kB/p65 (1:1500; ab16502), anti- $\beta$-catenin (1:1500; ab32572), anti-TGF$\beta(1: 1500 ; \quad a b 92486)$ and GAPDH (1:2000; ab181602). Membranes were rinsed with TBST (Thermo Fisher, USA) three times and incubated with secondary antibodies marked by HRP at room temperature for $1 \mathrm{~h}$. Finally, BeyoECL Moon (Beyotime, Shanghai, China) was added to membranes for visualization.

\section{Statistical analysis}

All data were displayed as mean \pm SD and analyzed by SPSS 22.0 (IBM, USA). All experiments were repeated 3 times. T-test was used for analysis between two groups, and groups more than two were compared by oneway ANOVA. $P<0.05$ was considered to have statistical significance.

\section{RESULTS}

Expression of MALAT1 is upregulated in DSS-induced colitis-like FHC cells and inhibited cell viability

After cells were induced by DSS, expression of MALAT1 in normal colorectal mucosal cell line FHC and DSS- induced FHC cells were evaluated by RT-qPCR and the results (Figure 1A) showed that MALAT1 expression was significantly $(\mathrm{P}<0.05)$ upregulated in DSSinduced $\mathrm{FHC}$ cells compared to the normal $\mathrm{FHC}$ cells. CCK-8 assay used for analysis indicated that DSS-induced FHC cells had lower viabilities than normal FHC cells (Figure 1B). After oeMALAT1, si-MALAT1 or their controls was transfected into DSS-induced FHC cells, expressions of MALAT1 were verified by RTqPCR. The expression level of si-MALAT1 in DSS-FHC cells was significantly $(P<0.05)$ reduced as shown in Figure $1 \mathrm{C}$. Also. cell viabilities were detected and the results, revealed that down-regulation of MALAT1 expression promoted cell viabilities, while its upregulation inhibited viabilities of the DSS-induced FHC cells (Figure 1D).

MiR-30c-5p directly binds to MALAT1, inhibits its expression and promotes viabilities of DSS-induced FHC cells

MiR-30c-3p was predicted to have binding site with MALAT1 using bioinformatics Starbase as shown in Figure 2A. Luciferase report assays demonstrated that miR-30c-5p mimics significantly $(P<0.05)$ decreased luciferase activity in MALAT1 wild type group while no significant change was observed in the other groups, confirming a binding site for miR-30c-3p (Figure 2B). Moreover, regulation of miR-30c-5p by MALAT1 was investigated. Through RTqPCR, expressions of MALAT1 were significantly $(P<0.05)$ lower in miR-30c-5p mimics group while it is higher in the miR-30c-5p inhibitor group compared to their negative control groups (Figure 2C). The effect of miR-30c-5p on cell viabilities was examined and the results (Figure 2D) highlighted that upregulation of miR-30c-5p 
increased cell viabilities in DSS-induced FHC cells and inhibition of miR-30c-5p reduced it.
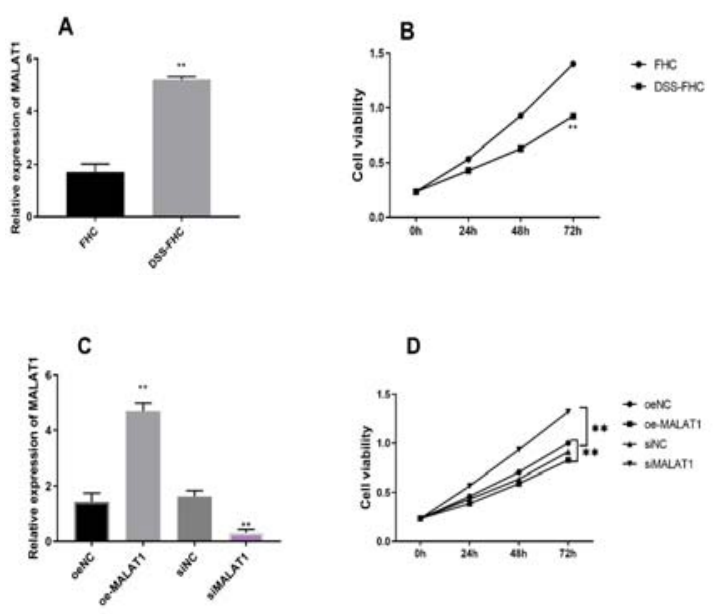

D

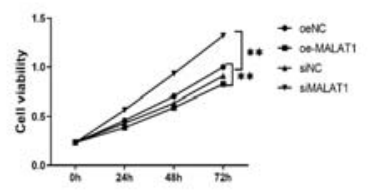

Figure 1: Expression of MALAT1 is upregulated in DSS-induced FHC cells and inhibited cell viability. (A) RT-qPCR evaluated MALAT1 relative expressions in normal FHC and DSSinduced FHC cells. (B) Cell viabilities were determined through CCK-8 assays in FHC and DSS-induced FHC cells. (C) RT-qPCR measured expressions of MALAT1 in four transfected groups of DSS-induced FHC cells. (D) CCK-8 assays evaluated cell viabilities in transfected DSS-induced FHC cells. ${ }^{* *}: P<0.05$.
A
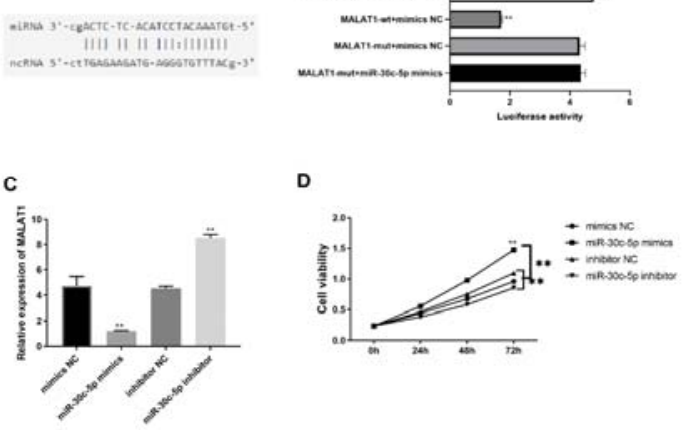

Figure 2: MiR-30c-5p directly binds to MALAT1, inhibits its expression and promotes viabilities of DSSinduced FHC cells. (A) Starbase V2.0 predicted the binding between MALAT1 and miR-30c-5p. (B) Luciferase reporter assay measured the luciferase activities in the DSS-induced FHC cells co-transfected with MALAT1-wt or MALAT1-mut and miR-30c-5p mimics or mimics NC. (C) RT-qPCR determined the relative expressions of MALAT1 in the cells after regulation of the expression of miR-30c-5p through transfection. (D) CCK-8 assay assessed cell viabilities in miR-30c-5p mimics, miR-30c-5p inhibitor and the respective negative control groups. ${ }^{* *}$ : $P<0.05$

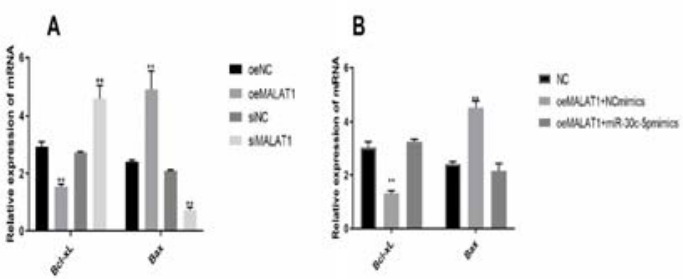

Figure 3: MiR-30c-5p mimics reduced cell apoptosis induced by overexpressed MALAT1. (A) The mRNA levels of Bcl-xl and Bax in DSS-induced FHC cells with different expressions of MALAT1 were examined by RT-qPCR. (B) The mRNA levels of Bcl-xl and Bax in oe-NC, oe-MALAT1 and combined group of oeMALAT1+miR-30c-5p mimics in DSS-induced FHC cells as determined by RT-qPCR. **: $\mathrm{P}<0.05$

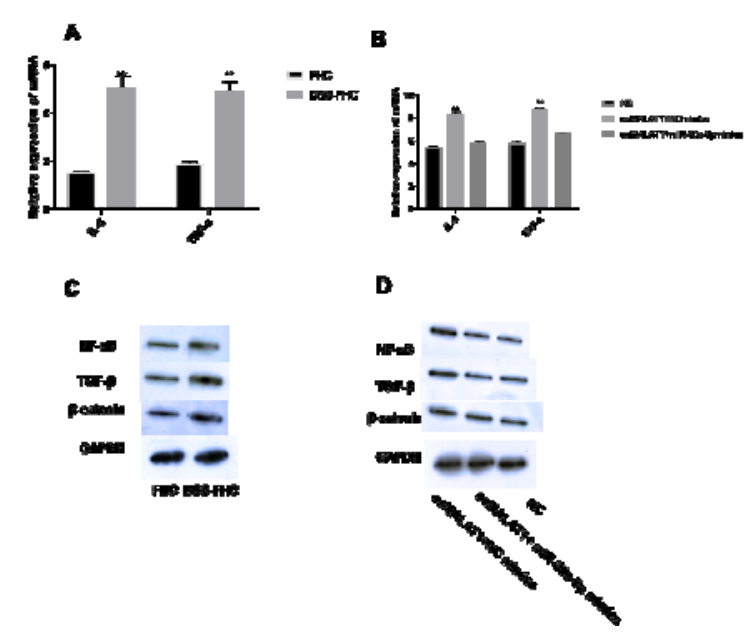

Figure 4: MALAT1/miR-30c-5p regulates NF-kB/TGF$\beta /$ Wnt- $\beta$-catenin signaling pathway. RT-qPCR measured the mRNA levels of IL-8 and TNF- $\alpha$ in: (A) FHC and DSS-induced FHC cells (B) The sub-groups of DSS-FHC cells transfected with oe-MALAT1 and combined group of oe-MALAT1+miR-30c-5p mimics; Western blot checked the protein expression levels of NF-kB/TGF- $\beta / \beta$-catenin in: (C) FHC and DSS-induced FHC cells (D) The sub-groups of DSS-FHC cells transfected with oe-MALAT1 and combined group of oe-MALAT1+miR-30c-5p mimics. ${ }^{* *}: \mathrm{P}<0.05$

\section{MiR-30c-5p mimics reduced cell apoptosis induced by overexpressed MALAT1}

Compared to the negative control group, expression of $\mathrm{Bcl}-\mathrm{xL}$ was significantly $(\mathrm{P}<0.05)$ lower in the oe-MALAT1 DSS-induced FHC cells, while that of Bax was higher. Meanwhile, the knockdown of MALAT1 enhanced the expression of $\mathrm{Bcl}-\mathrm{xL}$ while that of Bax was inhibited (Figure $3 A)$. MiR-30c-5p mimics reversed the functions of MALAT1 in regulating apoptotic biomarkers of colitis-like FHC cells (Figure 3B).

Trop J Pharm Res, September 2020; 19(9): 1874 
MALAT1/miR-30c-5p regulated NF-KB/TGF$\beta /$ Wnt $-\beta$-catenin signaling pathway

Expressions of IL-8 and TNF- $\alpha$ in FHC and DSSinduced FHC cells were detected by RT-qPCR (Figure 4A), which displayed that expressions of IL-8 and TNF- $\alpha$ were upregulated in DSSinduced FHC cell group. Besides that, upregulation of MALAT1 increased expressions of IL-8 and TNF- $\alpha$ in DSS-induced FHC cells (Figure 4B). NF-kB/TGF- $\beta / \beta$-catenin proteins were examined by Western blot in $\mathrm{FHC}$ and DSS-induced FHC cells and the results (Figure 4C) highlighted that the signaling pathways were activated in DSS-induced colitis-like FHC cells. The oe-MALAT1 was observed to enhance proteins related to the signaling pathways while miR-30c-5p mimics was observed to suppress the activating effect by oe-MALAT1 in colitis-like FHC cells (Figure 4D).

\section{DISCUSSION}

Ulcerative colitis is a chronic non-specific inflammatory disease with unclear causes in pathology. It is a normal disease in adults between 30 to 40 years old and morbidity is increasing worldwide [15]. Studies also proved that patients with UC have much higher risk of having colorectal cancer [16]. For detecting UC in humans, several models which include spontaneous colitis, genetically modified and induced colitis models have been developed [17]. Among them, induced colitis model is the model achievable by chemical drugs, such as trinitrobenzene sulfonic acid (TNBs) and DSS [18]. DSS-induced colitis model could build chronic and acute models with similar symptoms like humans. However, the mechanism of DSS model is still unknown. Researches indicated that DSS could cause toxic damage to colon epithelial barrier, leading to increased permeability of the intestinal mucosa to induce inflammations. Therefore, in this study, DSS was employed to induce $\mathrm{FHC}$ cell line in vitro to achieve inflammatory colitis cells.

The current study disclosed that MALAT1 was upregulated in DSS-induced colitis-like FHC cells compared to the control normal FHC cells. Also, the down-regulation of MALAT1 expression promoted DSS-induced FHC cell viability and inhibited apoptotic biomarkers, suggesting that MALAT1 functions as an inhibitor which could suppress inflammations and cell apoptosis, as well as promote cell proliferation in colitis in vitro. LncRNAs and miRNAs affect disease progression through regulation of each other. Researches pointed out that IncRNAs mainly regulates miRNAs in three ways: IncRNAs could bind to the 3'-UTR of miRNAs to suppress negative regulation of miRNAs to mRNA [23]; IncRNAs could form precursors of miRNAs and regulate expressions of target genes [20]; InRNAs could also have the endogenous miRNA sponge ability to inhibit expressions of miRNA in diseases [24]. To investigate the regulatory role of miR-30c-5p, Starbase V2.0 was used to predict the target of MALAT1 being miR-30c-5p, and this observation was further confirmed through luciferase reporter assay. The outcome verified the binding sites between MALAT1 and miR-30c-5p. The effects of the interactions between the two genes were examined through RT-qPCR and the outcome revealed that there was an inter-inhibitory effect within the pair of genes in DSS-induced FHC cells. Expressions of miR-30c-5p were evaluated with different expressions of MALAT1 in the treated cells. Upregulation of MALAT1 inhibited the expression of miR-30c-5p, while the knockdown of MALA1 promoted the expression of miR-30c-5p. Cell viabilities were also detected which displayed that overexpression of miR-30c-5p enhanced cell viabilities and inhibition of miR-30c-5p suppressed cell viabilities.

Other studies have indicated that overexpression of MALAT1 reduced the expression of tumor suppressor PSF [19]. Meanwhile, in CaSki cell line of cervical cancer, down-regulated MALAT1 decreased expression of $\mathrm{Bcl}-2$ and $\mathrm{Bcl}-\mathrm{xL}$ and significantly promoted the expressions of caspase-3, -8 and Bax, which linked MALAT1 to be an anti-apoptotic gene in cervical carcinoma [20]. In colorectal cancer, MALAT1 promoted cancer cell proliferation, invasion and metastasis through AKAP-9 signaling pathway [21]. According to gene polymorphism between inflammatory and cell factors, reducing inflammation suppressed cancer progression effectively [22]. In the present study, further investigations were conducted to determine effects of the correlation between MALAT1 and miR-30c-5p on inflammatory cells. It was detected that in the DSS-induced FHC cells, expression of anti-apoptotic gene Bcl-xL was lower while that of apoptotic gene Bax was higher, when MALAT1 was overexpressed and MALAT1 was silenced. The inhibition of MALAT1 suppressed apoptosis in colitis-like cells. After the overexpression of miR-30c-5p, expression of $\mathrm{Bcl}-\mathrm{xl}$ was increased and that of Bax was decreased. These observations indicated that MALAT1's upregulation promoted cell apoptosis while miR-30c-5p mimics suppressed the effect of MALAT1 in apoptosis.

In colitis, activation of $\mathrm{Wnt} / \beta$-catenin signaling pathway is a kind of reaction related to 
inflammation, which played important roles in colic mucosa damages [25]. However, prolonged and sustained activation of Wnt signaling pathway might transform colitis to colorectal cancer [15]. Thus, overexpressed Wnt could increase malignant changes in colitis. NF-KB plays an important role of inducing inflammation and cancer [26,27]. TGF- $\beta$ is an inflammatory cytokine regulated by NF-KB, whose expression was up-regulated with activation of NF-KB $[28,29]$. The reversal influence of miR-30c-5p mimics on oe-MALAT1 in regulating cell viability, apoptotic biomarkers and inflammatory cytokines in relation to NF-kB/TGF- $\beta /$ wnt/ $\beta$-catenin signaling pathways were further investigated. Protein expressions of $\beta$-catenin, TGF- $\beta$ and NF$\mathrm{kB} / \mathrm{p} 65$ were analyzed by Western blot. The results revealed that expressions of these genes were higher in the inflammatory cells. With the upregulation of MALAT1 expression, miR-30c-5p mimics restored the function of MALAT1, indicating that miR-30c-5p suppresses the functions of MALAT1 through inhibiting activations of NF-kB/TGF- $\beta / W n t-\beta-c a t e n i n$ signaling pathway.

\section{CONCLUSION}

Upregulation of MALAT1 expression in DSSinduced colitis-like FHC cells promoted cell viabilities, while the expression of miR-30c-5p was inhibited. The inhibition of miR-30c-5p expression restored the functions of MALAT1 via NF-KB/TGF- $\beta /$ Wnt- $\beta$-catenin signaling pathway. Our findings suggest that MALAT1 could be a potential biomarker in a clinical stage for treating colitis.

\section{DECLARATIONS}

\section{Conflict of interest}

No conflict of interest is associated with this work.

\section{Contribution of authors}

We declare that this work was done by the author(s) named in this article and all liabilities pertaining to claims relating to the content of this article will be borne by the authors. All authors read and approved the manuscript for publication. BZ and TL contributed equally to this work.

\section{Open Access}

This is an Open Access article that uses a funding model which does not charge readers or their institutions for access and distributed under the terms of the Creative Commons Attribution License (http://creativecommons.org/licenses/by/ 4.0) and the Budapest Open Access Initiative (http://www.budapestopenaccessinitiative.org/rea d), which permit unrestricted use, distribution, and reproduction in any medium, provided the original work is properly credited.

\section{REFERENCES}

1. Baumgart DC and WJ Sandborn. Inflammatory bowel disease: clinical aspects and established and evolving therapies. Lancet, 2007. 369(9573): p. 1641-57.

2. Conrad K, D Roggenbuck, and MW Laass. Diagnosis and classification of ulcerative colitis. Autoimmun Rev, 2014. 13(4-5): p. 463-6.

3. Adams $S M$ and PH Bornemann. Ulcerative colitis. Am Fam Physician, 2013. 87(10): p. 699-705.

4. Zhang $Y Z$ and $Y Y$ Li. Inflammatory bowel disease: pathogenesis. World J Gastroenterol, 2014. 20(1): p. 919.

5. Silverberg MS et al. Toward an integrated clinical, molecular and serological classification of inflammatory bowel disease: report of a Working Party of the 2005 Montreal World Congress of Gastroenterology. Can J Gastroenterol, 2005. 19 Suppl A: p. 5a-36a.

6. Wirtz $S$ et al. Chemically induced mouse models of acute and chronic intestinal inflammation. Nat Protoc, 2017. 12(7): p. 1295-1309.

7. Tanaka $T$ et al. A novel inflammation-related mouse colon carcinogenesis model induced by azoxymethane and dextran sodium sulfate. Cancer Sci, 2003. 94(11): p. 965-73.

8. Melgar $S$ et al. Validation of murine dextran sulfate sodium-induced colitis using four therapeutic agents for human inflammatory bowel disease. Int Immunopharmacol, 2008. 8(6): p. 836-44.

9. Ponting $C P$ and TG Belgard. Transcribed dark matter: meaning or myth? Hum Mol Genet, 2010. 19(R2): $p$. R162-8.

10. Ji $P$ et al. MALAT-1, a novel noncoding RNA, and thymosin beta4 predict metastasis and survival in earlystage non-small cell lung cancer. Oncogene, 2003. 22(39): p. 8031-41.

11. Bernard $D$ et al. A long nuclear-retained non-coding RNA regulates synaptogenesis by modulating gene expression. Embo j, 2010. 29(18): p. 3082-93.

12. Lai MC et al. Long non-coding RNA MALAT-1 overexpression predicts tumor recurrence of hepatocellular carcinoma after liver transplantation. Med Oncol, 2012. 29(3): p. 1810-6.

13. Fan $Y$ et al. TGF-beta-induced upregulation of malat1 promotes bladder cancer metastasis by associating with suz12. Clin Cancer Res, 2014. 20(6): p. 1531-41.

14. Zhu M and J Xie. LncRNA MALAT1 Promotes Ulcerative Colitis by Upregulating IncRNA ANRIL. Dig Dis Sci, 2020.

Trop J Pharm Res, September 2020; 19(9): 1876 
15. Torres $\mathrm{J}$ et al. Ulcerative colitis as a progressive disease: the forgotten evidence. Inflamm Bowel Dis, 2012. 18(7): p. 1356-63.

16. Jess $T, C$ Rungoe, and $L$ Peyrin-Biroulet. Risk of colorectal cancer in patients with ulcerative colitis: a meta-analysis of population-based cohort studies. Clin Gastroenterol Hepatol, 2012. 10(6): p. 639-45.

17. Wirtz $S$ and MF Neurath. Mouse models of inflammatory bowel disease. Adv Drug Deliv Rev, 2007. 59(11): $p$. 1073-83.

18. Waldner MJ and MF Neurath. Chemically induced mouse models of colitis. Curr Protoc Pharmacol, 2009. Chapter 5: p. Unit 5.55.

19. Garen $A$ and $X$ Song. Regulatory roles of tumorsuppressor proteins and noncoding RNA in cancer and normal cell functions. Int J Cancer, 2008. 122(8): $p$. 1687-9.

20. Wilusz JE, H Sunwoo, and DL Spector. Long noncoding RNAs: functional surprises from the RNA world. Genes Dev, 2009. 23(13): p. 1494-504.

21. Yang $M H$ et al. MALAT1 promotes colorectal cancer cell proliferation/migration/invasion via PRKA kinase anchor protein 9. Biochim Biophys Acta, 2015. 1852(1): p. 16674.

22. Steigman SA et al. Optical properties of human amniotic fluid: implications for videofetoscopic surgery. Fetal Diagn Ther, 2010. 27(2): p. 87-90.
23. Faghihi MA et al. Expression of a noncoding RNA is elevated in Alzheimer's disease and drives rapid feedforward regulation of beta-secretase. Nat Med, 2008. 14(7): p. 723-30.

24. Wang $J$ et al. CREB up-regulates long non-coding RNA, HULC expression through interaction with microRNA372 in liver cancer. Nucleic Acids Res, 2010. 38(16): $p$. 5366-83.

25. Cosin-Roger $\mathrm{J}$ et al. M2 macrophages activate WNT signaling pathway in epithelial cells: relevance in ulcerative colitis. PLoS One, 2013. 8(10): p. e78128.

26. Clark MB et al. Genome-wide analysis of long noncoding RNA stability. Genome Res, 2012. 22(5): p. 885-98.

27. Hoesel $B$ and JA Schmid. The complexity of NF-kappaB signaling in inflammation and cancer. Mol Cancer, 2013. 12: p. 86.

28. Freudlsperger $C$ et al. TGF-beta and NF-kappaB signal pathway cross-talk is mediated through TAK1 and SMAD7 in a subset of head and neck cancers. Oncogene, 2013. 32(12): p. 1549-59.

29. Yao $L$ et al. Coreopsis tinctoria Nutt ameliorates high glucose-induced renal fibrosis and inflammation via the TGF-beta1/SMADS/AMPK/NF-kappaB pathways. BMC Complement Altern Med, 2019. 19(1): p. 14. 